\title{
The health of vulnerable adolescent girls: A strategic investment for double return
}

Jennifer Catino

Population Council

Follow this and additional works at: https://knowledgecommons.popcouncil.org/departments_sbsr-pgy

Part of the Family, Life Course, and Society Commons, Gender and Sexuality Commons, International Public Health Commons, and the Women's Health Commons How does access to this work benefit you? Let us know!

\section{Recommended Citation}

Catino, Jennifer. 2012. "The health of vulnerable adolescent girls: A strategic investment for double return," GIRLS FIRST! Perspectives on Girl-Centered Programming. New York: Population Council. 
A GIRLS FIRST! PUBLICATION

THE HEALTH OF VULNERABLE ADOLESCENT

GIRLS: A STRATEGIC INVESTMENT FOR DOUBLE RETURN

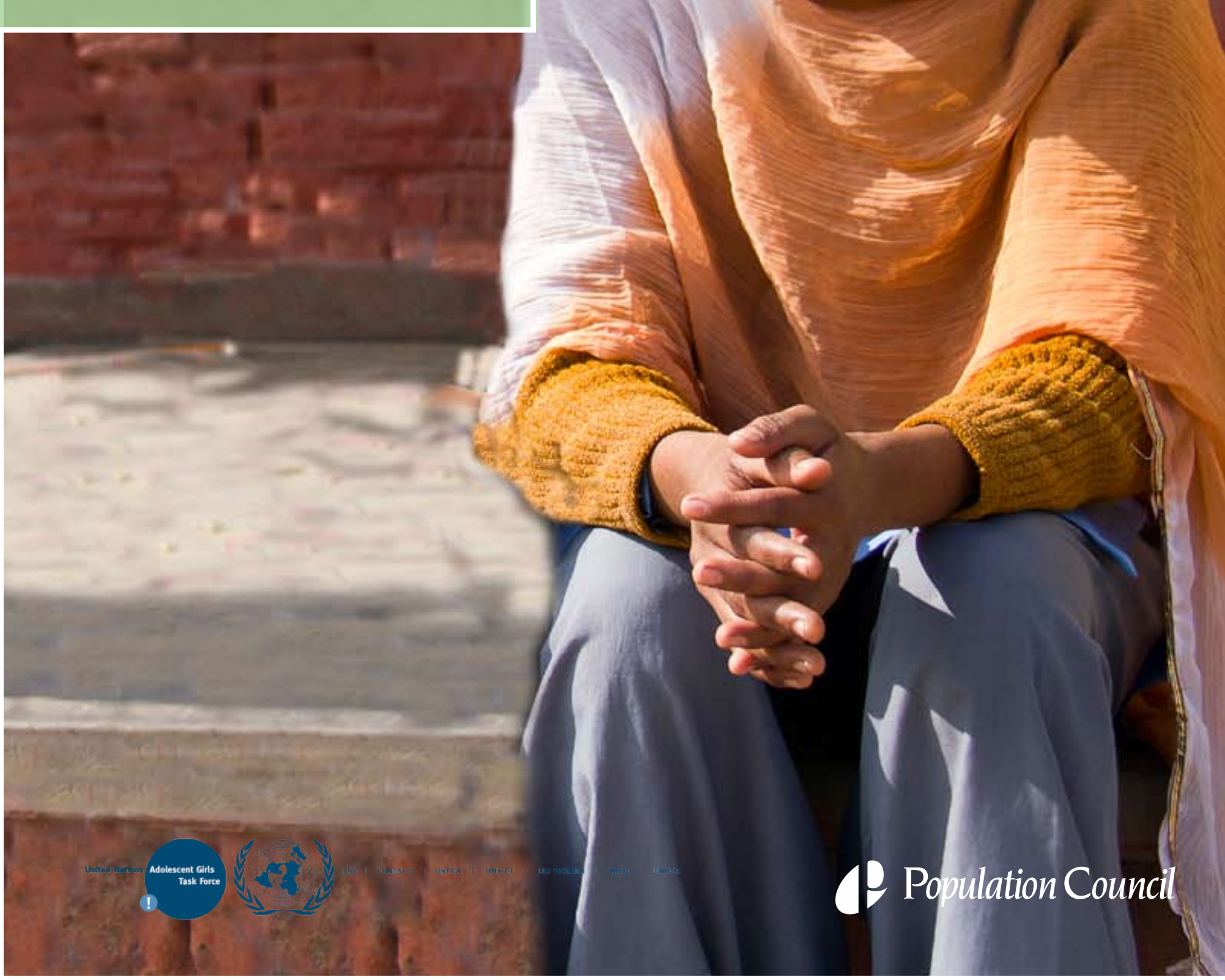




\section{GIRLS FIRST!}

\section{PERSPECTIVES ON GIRL-CENTERED PROGRAMMING}

The field of research and programs for adolescent girls has traditionally focused on sexuality, reproductive health, and behavior, neglecting the broader social and economic issues that underpin adolescent girls' human rights, overall development, health, and well-being. Further, efforts to improve girls' lives often spotlight those who control or influence their lives-parents, in-laws, boys, men, perpetrators-overlooking girls themselves.

GIRLS FIRST! Perspectives on Girl-Centered Programming is a set of five thematic Reviews, written by experts at the Population Council. They are snapshots of the knowledge base at a particular moment in this quickly changing field. They address the five strategic priorities defined in the UN Joint Statement, "Accelerating Efforts to Advance the Rights of Adolescent Girls" (March 2010), which represents the collective commitment of seven UN agencies to support governments and partners in advancing key policies and programs for the hardest-toreach adolescent girls. The Reviews therefore:

1. Explore where to go next with education for girls;

2. Outline innovative approaches to improving girls' health;

3. Reframe the field's approach to violence against girls;

4. Describe the best ways to cultivate girl leaders; and

5. Explain novel ways to collect and use data on adolescent girls.

The Reviews put forward innovative arguments for investing in girls and highlight promising practices. They express a forward-looking and evidence-based point of view on where the field must allocate resources in order to most quickly and effectively improve girls' lives.

These Reviews-while written by experts at the Population Council, an organization that has pioneered cutting-edge research and programming for vulnerable and marginalized adolescent girls-were catalyzed with leadership support from the UN Adolescent Girls Task Force. Additional moral and material support was provided by the Nike Foundation, the United Nations Foundation, and the David and Lucile Packard Foundation. These Reviews add to other programmatic guidance and toolkits now available and serve as an essential reference for anyone seeking to develop successful and sustainable policies and programs for girls. We hope that they will inspire innovative approaches in efforts that realize the rights of marginalized adolescent girls worldwide.

July 2012

Population Council and UN Adolescent Girls Task Force

Disclaimer

The Reviews on programming for adolescent girls in the areas of Education, Health, Reduction of Violence, Girls Leadership, and Data have been prepared by the Population Council for the UN Adolescent Girls Task Force (UNAGTF), with support from the Nike Foundation, the United Nations Foundation, and the David and Lucile Packard Foundation.

The views expressed in these Reviews are solely those of the authors and do not necessarily reflect the views of their donor partners.

(C) 2012 The Population Council, Inc. $\quad$ www.popcouncil.org 


\title{
THE HEALTH OF VULNERABLE ADOLESCENT GIRLS: A STRATEGIC INVESTMENT FOR DOUBLE RETURN
}

\author{
BY JENNIFER CATINO
}

\section{INTRODUCTION AND PREMISE........................................ 2}

\section{THE CURRENT LANDSCAPE}

Two foundations of health 2

Advances in child health during the past 30 yearsmany girls have benefited, but many have not. 2

IIIness and a loss of physical integrity in adolescent girls have social roots-and they begin to magnify at puberty .....2

There are health and related social risks that adolescent girls exclusively or predominantly experience. ... 3

Health-related behaviors set during adolescence can have lifelong health implications, not only for girls and women but for future generations. 5

Health systems do not meet the needs of vulnerable adolescent girls-either as consumers or providers of care and services.

\section{PROMOTED POLICIES AND PRACTICES} 5

Conduct targeted research on vulnerable adolescent girls' experience of particular and shared health problems. .5

Map girls' health status and closely related social experiences to understand the age-, gender-, and context-specific vulnerabilities of subgroups of girls and young women. 5

Conduct participatory research and test strategies to better understand and support the dual role of girls and young women as health-care consumers and providers ..... 7 Mitigate health risks to adolescent girls that arise owing to their lack of safety and the frequency with which they are threatened with or experience violence ....... 7 Develop adolescent girls' ability to think critically about their health and lives 7

Inform mass media with more specific scenarios about the risks to adolescent girls' health, and promote positive and realistic images of girls 7

Identify and test opportunities for using increasingly accessible technologies to improve girls' health and safety

Institute programs that target and support the critical puberty transition
Support the youngest first-time mothers, who experience a disproportionate and rising share of maternal ill health

Work outward from girls to best understand, and measure, the positive engagement of boys and young men in support of the health and well-being of vulnerable girls

Mobilize girls and young women to strengthen the health sector and expand their livelihood horizons .........9

Educate girls and young women to understand their rights and responsibilities as both health-care consumers and providers 10

\section{RESOURCES: LEARNING LAB PROGRAMS,} PUBLICATIONS, AND TOOLS

Abriendo Oportunidades: Working with girls in rural Guatemala to discover their health potential and reduce violence

Rwanda 12+: Focusing systematic attention on the potential and needs of the 12-year-old girl. 10

Berhane Hewan: Creating a place to support unmarried and married girls and the youngest first-time mothers ......10

Puntos de Encuentro: Addressing the nexus between violence and poor health.

It's All One Curriculum: Guidelines for a Unified Approach to Sexuality, Gender, HIV, and Human Rights Education 11

Investing When It Counts: Generating the Evidence Base for Policies and Programs for Very Young Adolescents 11

WHO Adolescent Job Aid: A handy desk reference tool for primary-level health workers. .11

Girl-Centered Program Design: A Toolkit to Develop, Strengthen, and Expand Adolescent Girls Programs ..........11 Empowering Young Women to Lead Change 11

CONCLUSION .................................................................11

NOTES AND REFERENCES ........................................ 12 


\section{INTRODUCTION AND PREMISE}

Worldwide there are 1.2 billion adolescents between the ages of 10 and 19. Nearly 90 percent of them live in developing countries, and approximately 600 million are female. ${ }^{1}$ While adolescence is normally a time of good health, numerous developmental and social changes occur during this period, many of which have health implications, especially for girls. Most of the hundreds of millions of girls and young women in the developing world live in conditions and circumstances that make them vulnerable to health and social risks. These adolescent girls are often poor, out-of-school, married, migrants, members of ethnic minorities, or engaged in unsafe labor.

Conditions for girls vary radically from one context to another. Girls from many of the poorest communities around the world continue to be plagued by communicable diseases, undernutrition, and harmful traditional practices; in other contexts, girls are experiencing rising rates of obesity, tobacco use, and depression. Both communicable and noncommunicable diseases require comprehensive multisector approaches to understand and respond to girls' interrelated health and social needs.

As such, approaches that help girls attain comprehensive knowledge, skills, and resources-both personally and in the environment around themwill go a long way toward enabling them to control their bodies and lives. The health sector must improve and become inclusive of girls to maximize its impact. Other sectors must also be mobilized to support girls and enable them to make choices and find opportunities that will positively influence their health and allow them to achieve their full potential.

The focus here is on the health risks and needs of vulnerable adolescent girls and the far-reaching opportunities available to them when strategic investments in their health, well-being, and problem-solving abilities are made.

Where it exists, available evidence should be integrated and built upon.
Evidence on specific health needs and required solutions for vulnerable subgroups of adolescent girls, however, is thin (adolescent health data collected overall is limited and not often disaggregated by sex, age, or other factors). ${ }^{2.3}$

The purpose of this briefing paper is twofold: to elaborate on girls' health challenges, and also the promise of investing in these girls. This briefing paper emphasizes ideas and innovations to help guide the field to better respond to, and maximize, the potential of the poorest girls in the poorest communities. A growing body of research shows that health, social, and economic progress will be achieved more rapidly and cost-effectively by focusing first on the poorest girls in the hardest-toreach places. Prioritizing equity within a global reality of economic uncertainty is not only fair, it works. ${ }^{4}$

\section{THE CURRENT LANDSCAPE}

\section{Two foundations of health}

Adolescence is the period during which two foundations of girls' health are established:

- Their own personal health with respect to sexual activity and a sense of control over their body, diet, and physical activity. It is during adolescence that lifelong behavioral patterns affecting health are often set, and these are often dictated by the social and economic environment in which adolescents develop.

Further, the education, health, and well-being of adolescent girls influences that of the children they will bear.

- Their ability to see themselves as agents of change with respect to their own and other's health.

This is a time when girls' skills, knowledge, and education should prepare them for safe livelihoods. Training girls to recognize and address health issues in their communities will set the stage for their participation in the health sector. It will mobilize them to become part of the solution to meeting their own and their community's health needs.

For example, adolescent graduates of the Abriendo Oportunidades program in rural Guatemala (young women aged $16+$ ) are equipped to learn and apply deeper skills and take on additional leadership roles in their communities. Because these young women share the local indigenous culture and language and have become known and trusted resources to community members, they are strategically positioned to provide primary health care information, basic health commodities, and referral for health services. The program is currently coordinating with community health systems to pilot training and support young female program graduates to take on health promotion roles in their families and communities, thereby filling an important human resource gap in rural areas and providing young women with professional skills, experience, and livelihood opportunities.

Table 1 gives concrete examples of ways that adolescents can be trained, supported, and compensated to deliver health solutions.

Advances in child health during the past $\mathbf{3 0}$ years-many girls have benefited, but many have not

Child survival has increased dramatically in the past 30 years. Since 1950, the child death rate has fallen by around 60 percent as a result of improving social and health conditions. ${ }^{5}$ Combined with continued high fertility in many parts of the world, this means that more and more children, both female and male, are now entering adolescence. $^{6}$

At the age of ten, most girls around the world are still in school. The past decade has seen great advances in girls' enrollment in primary school, with many regions achieving gender parity. ${ }^{7}$ Girls' school attendance during adolescence is correlated with delayed sexual initiation, later marriage and childbearing, lower rates of HIV/AIDS and other sexual and reproductive morbidities, and greater gender equality. ${ }^{8}$ Girls' educational opportunities, however, and their safety and health in and out of school, tend to decline by the time they are of secondary school age, ${ }^{9}$ as the critical time of puberty approaches. 


\section{TABLE 1 ADOLESCENT-DELIVERED COMMUNITY HEALTH SOLUTIONS}

\section{COMMUNITY HEALTH ISSUES}

Diarrheal disease

Respiratory disease

Malnutrition

Malaria

Unwanted pregnancy

Maternal mortality

Gender violence

Infant mortality

HIV/STIS

Obesity

Depression/mental health

Substance abuse

\section{ADOLESCENT-DELIVERED SOLUTION}

Promote hygiene, provide clean water, recognize symptoms, distribute ORS, timely referral to health services

Promote clean environment, recognize symptoms, timely referral

Promote balanced nutrition and healthy food preparation, recognize symptoms, distribute supplements and vitamins, lead development of home and community gardens

Promote safe environment, distribute bed nets, recognize symptoms, timely referral

Provide comprehensive preventive education, distribute condoms and some contraceptives, timely referral, lead single and married girls' clubs to build female assets

Recognize danger signs, timely referral, lead single and married girls' clubs to build female assets

Provide prevention information, recognize danger signs and areas, timely referral, lead girls' clubs to build girls' protective assets, develop safety plans

Recognize danger signs, timely referral

Provide prevention information, distribute condoms, timely referral for testing, counseling, care, and treatment

Provide prevention information, promote balanced nutrition and exercise, timely referral, lead girls' clubs to build female assets

Recognize danger signs, timely referral, lead girls' clubs to build female assets, social support, and self-help

Recognize danger signs, timely referral, lead girls' clubs to build female assets, social support, and self-help
Illness and a loss of physical integrity in adolescent girls have social roots, and they begin to magnify at puberty

Adolescence is normally characterized by low levels of disease and death. Until puberty, girls and boys in most parts of the world are experiencing improvement in opportunities for education, health, and personal development. ${ }^{10}$ If girls are not healthy at age 12-and many are not, especially in the poorest communities of the world-the causes are mainly social and related to gender discrimination.

Around the age of 12 , the paths for poor girls and boys frequently begin to diverge, with opportunities for boys continuing to expand, while those for girls often contract. Gender-specific emergent issues for girls around the time of puberty are illustrated in the table on the next page. Following the onset of menstruation, adolescent girls are often accorded the status of adult women and they experience increased gender discrimination that can result in withdrawal from school, increased work burden, loss of peer support and increase in social isolation, pressure for early marriage often as an economic survival strategy, and increased genderbased violence.

“What happens to a girls' health around the age of 12 determines her future-and that of her family, community, and country."11

Many consequences of the rapid physical, emotional, and social changes that vulnerable adolescent girls face are rooted in gender inequality and poverty. These consequences contribute to a range of interrelated health threats that are particular and often grave-not only affecting the well-being and development of girls and young women themselves, but also that of their children, communities, and nations.

There are health and related social risks that adolescent girls exclusively or predominantly experience

Menstrual management can be a stifling issue for poor adolescent girls. In resource-constrained environments, girls do not have the supplies or facilities they need to be able to attend school, work, or otherwise move around 
freely and comfortably during their menses. Discomfort, embarrassment, and the threat of pregnancy once menstruation has begun frequently combine to force girls out of the public sphere and into situations of domestic confinement and social isolation. ${ }^{12}$

Girls exclusively are subject to female genital mutilation (FGM), a forcible removal of part of their body. An estimated 130-140 million girls and women have undergone FGM, and 3 million girls are at risk of undergoing the practice every year. ${ }^{13}$ FGM constitutes a gross human rights violation and presents a grave danger to girls' health, often resulting in hemorrhage, infection, painful intercourse, urinary-system damage, scarring, and other serious long-term disabilities. It also increases risks during pregnancy and delivery and is associated with poor birth outcomes.

Another example of harmful traditional practices disproportionately inflicted on girls is child marriage. Adolescent girls are much more likely than boys to be married as children, and forcibly initiated into sexual activity as children. Approximately one-third of adolescent girls in developing countries (excluding China) are married before age 18 , and in some countries nearly 30 percent are married before age $15 .{ }^{14}$ The poorest girls, those most likely to be married youngest, are at the highest risk of HIV and sexually transmitted infections (STIs), premature and frequent childbearing, high rates of maternal morbidity and mortality, and high levels of child mortality and ill health. ${ }^{15}$

In most places in the world, girls' first sexual activity occurs during late adolescence, between the ages of 15 and 19. Human papillomavirus (HPV) affects relatively young women, nearly 90 percent of them in developing countries, and is the largest single cause of years of life lost to cancer in the developing world. In contexts where the HPV vaccine is available, girls need it before sexual initiation. ${ }^{16}$ Early sexual activity in girls is most often associated with coercion and violence. The younger a female is at first sex, the more likely her sexual initiation was forced. ${ }^{17}$ Early sex, especially by rape or incest, has a range of health implications-from unwanted pregnancy and STIs to long-term mental and physical health consequences. Girls who experience sexual violence-and there are many-require an immediate and effective health-system response that includes emergency contraception (EC) and HIV post-exposure prophylaxis (PEP), as well as mental health and legal services. ${ }^{18}$

Evidence shows that few young women use a contraceptive method of any kind at first sex. ${ }^{19}$ Adolescent girls' access to contraception is limited because of their own lack of information and skills, and because most reproductive health services around the world are not designed to reach them or meet their needs. Once adolescents are sexually active, they need reliable access to contraception and appropriate health services for regular STI and reproductive health screening.

The implications of pregnancy for poor adolescent girls are often grim. Complications related to pregnancy and childbirth are among the leading causes of death among 15-19-yearolds in developing countries. ${ }^{20}$ Pregnancy combined with low social status often results in nutritional deficits (such as anemia) that contribute to miscarriage, stillbirth, premature delivery, perinatal mortality, and increased risk of vertical HIV transmission and obstetric fistula, particularly in the youngest first-time mothers. ${ }^{21}$

Because many adolescent girls experience unwanted pregnancy, often the result of forced or coerced sex, rates of unsafe abortion are high. Evidence from Africa indicates that girls aged 15-19 account for 25 percent of unsafe abortions. ${ }^{22}$ Due to a combination of biological and social factors, including sexual violence and rape, sex with older men, exchange of sex for money and other necessities, limited information, ability to negotiate condom use, and access to health services, young women are particularly vulnerable to HIV infection particularly in sub-Saharan Africa where the epidemic rages. ${ }^{23}$ Overall, girls are more likely than boys to experience all forms of sexual harassment and abuse, al-
EMERGENT ISSUES FOR GIRLS BY AGE 12*

Sexual maturation

Consolidation of gender norms

Disproportionate care and work burden

Withdrawal from, and lack of safety in, public spaces

School safety and drop out

Loss of peers

Pressure for early marriage

Harmful traditional practices

Migration for work

Subject to sexualized and consumerist media

*Bruce, J. 2010. Investing in Adolescent Girls: Building the Health, Social, and Economic Assets of the Poorest Girls in the Poorest Communities. DFID presentation, London.

though underreporting by both sexes remains a problem. ${ }^{24}$

Poor girls also experience a distinct and often more onerous domestic work burden as compared with boys. As a result, they experience high accident rates, such as falls and burns, and exposure to toxins from the materials and technologies used in domestic chores, such as cooking. ${ }^{25}$ Many girls from poor communities are forced to migrate in search of greater educational or employment opportunities, or to flee forced child marriage or other difficult circumstances at home. Of the 1 billion migrant workers in the world, 72 percent are female. Migrant workers are frequently undocumented and tend to get paid less, work in demanding and dangerous jobs, and are frequently tricked or sold into the sex trade. ${ }^{26}$ The health implications for migrant girls are clearly distinct and significant, requiring tailored and targeted response by the health sector and others.

Overall, poor adolescent females experience a particular and dispropor- 
tionate health burden due to social vulnerabilities related to gender inequality, discrimination, and poverty. ${ }^{27}$ Girls' disadvantaged social position relative to boys and men is at the root of most of these vulnerabilities, including:

- School drop out before essential education and health benefits are conveyed;

- Marriage before girls are physically and emotionally mature;

- Forced sexual initiations and other forms of violence;

- Limited employment options, which are often unsafe and exploitative.

Health-related behaviors set during adolescence can have lifelong health implications, not only for girls and women but for future generations

Health-related behavior patterns, such as diet and physical activity, are often set during adolescence. Poor habits can lead to being overweight and to obesity. Obese adolescents tend to stay that way into adulthood, thereby increasing their risk for diabetes and cardiovascular disease. While adolescent girls in many countries still suffer from undernutrition, data from 20 low- and middleincome countries show that about 12 percent of school-going 13-15-year-old girls are overweight. ${ }^{28}$ Despite physical activity's known benefits for physical and mental health, data from 36 lowand middle-income countries indicate that 86 percent of girls do not meet recommended levels of physical activity-a far higher proportion than among boys.

Adolescence is a natural time of emerging curiosity and experimentation, however there can be negative health outcomes associated with prolonged substance use and abuse. Adolescent girls are increasingly using tobacco and alcohol, and evidence shows that tobacco advertising is increasingly targeting girls and women. ${ }^{29}$

Table 2 highlights health-related issues and conditions experienced by adolescent girls, the potential health consequences, and what can be done to mitigate risk.
Health systems do not meet the needs of vulnerable adolescent girls-either as consumers or providers of care and services

The health sector plays a critical role in protecting and ensuring the health of adolescent girls, but reaching the poorest girls in the poorest communities also requires moving beyond the clinic walls. By definition, marginalized subgroups of girls are difficult to find and hard to reach, making it essential to know where they are and go there..$^{30}$ The emergence of "youth-friendly health services (YFHS)," which aim to be more appropriate for, and accessible to, young people by offering a comprehensive range of services, extending hours, ensuring confidentiality and privacy, making facilities welcoming, training personnel to work effectively with adolescents, and reducing cost barriers, is an important step in the right direction. The WHO has developed a job aid for YFHS ${ }^{31,32,33}$ and many organizations have contributed tools and guidance. International policymakers and national governments are increasingly developing standards and guidelines, however implementation has been uneven and often does not reach poor girls.

An ongoing need exists for bringing essential health information and services to vulnerable girl subgroups where they can be found: early, when they are still in school; in their communities; in their workplaces; and through nonhealth institutions and facilities where they are more likely to congregate (markets, neighborhood shops/ kiosks, churches, local nongovernmental organizations, and community-based organizations). Alternative approaches and strategies will also be required to reach these girls appropriately and to improve their health and safety, including outreach and community-based distribution of health commodities; mobile health services; and social marketing and use of emerging technologies, such as cell phones. While girls can and should play a role in formal, facilitiesbased health-service delivery, efforts to reach them can be particularly creative and effective at the grassroots level.
As formal and informal providers and caregivers within the health system and at the family and community levels, girls and young women are already major contributors in the provision of health care. Despite their disproportionately large roles at the more primary levels, females are rarely represented in senior-level positions, tending to be concentrated in lower-paid jobs and exposed to greater occupational risks. In their roles as informal health-care providers at home and in the community, girls and young women are often unsupported, unrecognized, and unremunerated. ${ }^{34}$ Turning this situation around to train, support, and compensate young females to enter the health sector can have double benefits. Some girls, even in the poorest communities, have advanced in their education. These women can help close the human-resource gaps and bring quality health information and services to the very subpopulations to which they belong. This effort can both expand the reach of the health sector and create viable livelihoods for young women.

\section{PROMOTED POLICIES AND PRACTICES}

\section{Conduct targeted research on vulnerable adolescent girls' experience of particular and shared health problems}

Despite the fact that adolescent females are both biologically and socially different from males, clinical studies and research around the world has focused primarily on adult males as study subjects. This approach leaves vast scientific evidence gaps with regard to when and how different diseases impact females, and primarily how treatment protocols may need to vary by age and sex. Studies have found that the burdens of young age and female gender compound the biological and social risks and consequences experienced by adolescent girls. For example, adolescent girls are particularly vulnerable to malaria. In many sub-Saharan African settings, adolescents are often parasitemic and anemic when they first be- 


\section{TABLE 2 HEALTH RISKS AND NEEDS OF VULNERABLE ADOLESCENT GIRLS}

HEALTH-RELATED ISSUES

FOR ADOLESCENT GIRLS

Malnutrition and

undernutrition

Physical and emotional changes during puberty

Menstruation

School dropout

Child marriage

Early pregnancy

Harmful traditional practices, including female genital cutting (FGC)

Physical and sexual violence

Internalization of restrictive gender norms

Obesity

Smoking, drugs, and alcohol

Depression and mental health disorders

Unsafe and exploitive domestic and other labor

\section{POTENTIAL HEALTH CONSEQUENCES}

Anemia; stunting; cognitive disabilities; intergenerational transmission

Physical discomfort; emotional confusion; depression; social withdrawal

Physical discomfort; embarrassment; social withdrawal

Limited access to health education and services; social isolation and withdrawal; depression; increased labor burden and risk of accidents and exploitation; pressure to marry early

Child marriage occurs before the legal age of consent and can lead to physical and sexual violence and abuse; social isolation and withdrawal; premature pregnancy; risk of HIV and other STIs

Premature pregnancy can lead to maternal morbidity (such as fistula) and mortality; infant morbidity and mortality; unsafe abortion

Physical pain; infection; short-, medium-, long-term morbidity and mortality

Short- and long-term morbidity and mortality; depression and suicide

Social isolation; decreased mobility and autonomy; increased gender discrimination and gender-based violence

Physical discomfort; depression; social withdrawal; early-onset hypertension and diabetes

Impaired judgment correlated with increased SRH risk, accidents, and injury; chronic health conditions

Suboptimal functioning; social withdrawal; eating disorders; suicide

Physical exhaustion; accidents and injuries; emotional, physical, and sexual abuse; depression and anxiety

\section{WHAT IS NEEDED TO MITIGATE RISK}

Access to health information; equal and constant access to nutritious, balanced food sources; nutritional supplements and vitamins

Access to comprehensive accurate information and social support; privacy and supplies to maintain personal hygiene; safe place to meet peers and receive mentoring and life skills

Knowledge of female reproductive functions, feminine hygiene; access to menstrual-management supplies (pads, tampons, nonsteroidal anti-inflammatory medication); access to privacy and clean water at home, school, and work

Knowledge of right to education and health care; access to quality sexuality education and health services through school; safe place to meet peers and receive mentoring and life skills

Knowledge of right to legal age of marriage; skills and power to negotiate desired age of marriage; skills and power to negotiate safe and consensual sex; access to health information and services; safe place to meet peers and receive mentoring and life skills

Access to health information, contraception, and broad sexual and reproductive health (SRH) services and options counseling; safe place to meet peers and receive mentoring and life skills

Knowledge of right to bodily integrity; skills and power to negotiate; access to health information and services; safe place to meet peers and receive mentoring and life skills

Knowledge of rights; promotion of equitable gender norms; immediate access to range of legal, health, and social services; access to EC, PEP, and emergency services in case of rape; HIV/STI screening and treatment; skills and power to negotiate safety and refuge; safe place to meet peers and receive mentoring and life skills; preventive safety plan

Knowledge of rights; promotion of equitable gender norms; access to social services; social support; safe space to meet peers and receive mentoring and life skills

Access to information, resources, and social support for favorable nutrition; access to healthy affordable food; safe places to undertake physical activity and sports, meet peers, and receive mentoring and life skills

Knowledge and information about risks and signs of addiction; peer and social support

Knowledge and information about symptoms; social and professional support

Knowledge of legal age of work; skills and power to negotiate safety and fair compensation; access to health information and services; safe place to meet peers and receive mentoring and life skills 
come pregnant. According to data from Malawi, both nonpregnant and pregnant adolescent girls had significantly higher parasite levels than women who were more than 19 years old. ${ }^{35}$ Gender and age-specific protocols are therefore needed in researching the etiology and illuminating the gender-specific elements of girls' and young women's infectious and chronic diseases. While it is known that girls and women are often treated later and less aggressively than their male peers, ${ }^{36}$ the health, social, and financial cost implications for said biases remain unclear.

Map girls' health status and closely related social experiences to understand the age-, gender-, and context-specific vulnerabilities of subgroups of girls and young women

The data exist to map the demographic and health vulnerabilities of groups of adolescent girls. Using such data would help in determining where investments-whether in policies and programs, or in money and resourcesare most urgent and critical. Mapping can be used to guide decisions about investing in the health-care infrastructure. For instance, mapping can be used to see where community-based support-say, to prevent unwanted pregnancy and support adolescent girls experiencing unsafe pregnancyis most needed. Program experience, in Guatemala and elsewhere, shows how adolescent girls themselves can be engaged in mapping exercises. The girls can incorporate their perspectives on health and safety into mapping efforts and share their ideas about ways to improve access to, and quality of, health services. This approach can be particularly effective when attempting to prevent gender violence. Girls can show program staff where-and explain when-they feel safe and unsafe in their communities and neighborhoods. Program staff and girls themselves can collaborate to design context-specific programs to reduce risk and increase security. These programs might include strategies to protect girls and young women as well as to promote more equitable gender norms. ${ }^{37}$
Conduct participatory research and test strategies to better understand and support the dual role of girls and young women as health-care consumers and providers

It is important to identify the knowledge and skills that girls and young women feel they need in order to create a more equitable, responsive, and effective health system. Such a system would maximize their contributions rather than exploit and discriminate against them. A recent workshop in Guatemala underscored the energy and intelligence with which girls describe their interrelated needs. ${ }^{38}$ Below are examples of the types of health, social, and economic resources adolescent girls believe they need:

- Knowledge about the signs and dangers of gender violence;

- Knowledge and capacity to prevent unintended pregnancy;

- Capacity to react and respond to interfamilial violence (have an emergency plan);

- Knowledge about what health resources exist in and around the community;

- Knowledge about where to go for help in an emergency;

- Knowledge about whom to reach out to if they have been abused physically or sexually;

- Knowledge about human rights;

- Recognition of their rights by families, communities, schools;

- Knowledge about labor laws;

- The capacity to demand the continuation of their education;

- The opportunity to participate in civic activities;

- Knowledge about their cultural identity;

- Sense of self-confidence and efficacy.

Responsive programming that provides girls with this information and equips them with the skills and support to act on it-on behalf of themselves and others-can go a long way toward transforming girls into "health assets" in their own lives and communities.
Mitigate health risks to adolescent girls that arise owing to their lack of safety and the frequency with which they are threatened with or experience violence

Girls in most parts of the world face the threat of violence on a daily basis-at home, in public spaces, in school. Gender-based violence and girls' exposure and experience from very young ages has become the norm. Duty bearers, such as teachers, health workers, and police, lack awareness of laws, policies, and systems to protect and defend girls and do not enforce these safeguards. Health and social services are generally ill-equipped to prevent and respond to gender-based violence, particularly as it affects adolescent girls. The insidious, chronic reality of such violence restricts, represses, and forces girls into other dangerous situations-they sometimes flee their homes, or even take their lives. ${ }^{39}$ Girls often retreat into social isolation to protect themselves from the threat of violence, further cutting themselves off from any existing, if limited, health information and services. Turning this situation around requires an ecological approach: Efforts must be made to build the social, health, and economic assets of vulnerable girls. Additionally, policymakers and communities must strive to favorably change the girls' conditions to make them safer. A range of innovative efforts to test safety strategies is beginning to emerge,${ }^{40}$ but more needs to be done to identify effective strategies and take them to scale.

Develop adolescent girls' ability to think critically about their health and lives

Many of the girls most in need of information and skill-building are not socially connected to schools or other service-delivery providers, therefore programs that genuinely strive to reach the poorest girls in the poorest communities must develop innovative ways of finding and reaching those segments. To build girls' broader life and critical-thinking skills, groundbreaking approaches to health and sexuality education can and must be developed and implemented. It's All One Curricu- 
lum $^{41}$ is one such pioneering tool for teaching and transferring these skills. It gives girls broad information, resources, support, and power to make decisions about their lives-and their bodies.

Inform mass media with more specific scenarios about the risks to adolescent girls' health, and promote positive and realistic images of girls

The constant barrage of media images of girls and women around the world is mainly counterproductive in terms of communicating empowering information and portraying normal, healthy, and balanced role models for adolescent girls. On the contrary, these images often grossly distort and reinforce negative, oppressive, and destructive gender stereotypes. Such depictions undermine girls' ability to develop a healthy self-image as they transition from child to adult. Positive and realistic alternatives are needed, such as those put forward by Puntos de Encuentro $^{42}$ in Nicaragua. The Nicaragua experience reveals how media representations that are honest and real, age-appropriate, and sensitive to issues of gender, sexual-orientation, and race can be engaging, informative, and attitude-changing.

Identify and test opportunities for using increasingly accessible technologies to improve girls' health and safety

Girls in the poorest and most remote communities around the world have increasing access to information and technology, which can and should be explored and tested to promote health and safety. A study in Brazil found that 84 percent of girls have mobile phones and 82 percent have used the Internet. ${ }^{43}$ The Mobile Alliance for Maternal Action (MAMA) was launched to catalyze the power of mobile technology in delivering health information to expectant mothers in Bangladesh, India, and South Africa. Pregnant females receive information delivered via mobile phone about how to care for themselves during pregnancy, dispel myths and misconceptions, highlight danger signs, and connect with local health services. ${ }^{44}$ While this program has yet to be evaluated for effectiveness and there are not yet many such initiatives that directly target adolescent girls, Information and Communication Technologies (ICTs) may help deliver timely crucial information to girls and help them connect with each other and with networks and services that can enhance their health, safety, and well-being.

\section{Institute programs that target} and support the critical puberty transition

Health systems around the world are geared toward dealing with girls after the worst outcomes have already occurred-including unsafe, forced sex, and unwanted early pregnancies. Adolescent girls at greatest risk tend to get off track soon after puberty. Hence, it is essential to start programs for these girls earlier-when they are as young as age eight or ten-and to reach them through schools when the majority can be identified and reached most easily. Approaches such as a "Wellness Check" (see Table 3), proposed as a comprehensive health- and social-preventive screening for girls and boys around the age of puberty, can help keep young people, especially vulnerable girls, on track. Such strategies can also ensure that girls are in good health and are receiving sufficient education and appropriate social support for a positive transition through adolescence. ${ }^{45}$

\section{Support the youngest first-time mothers, who experience a disproportionate and rising share of maternal ill health}

Married girls comprise the majority of sexually active females in the developing world, however they tend to be overlooked by youth and sexuality-education programs, which focus mainly on young people who are unmarried and in school. Married girls are also neglected by reproductive health and development programs, which focus on adult women. Young first-time mothers tend to suffer from low social mobility, limited access to reliable information, and lack of reproductive decisionmaking power. They are often at increased risk of violence compared to women who marry later, and they have uninformed and unprotected relations with husbands, who, in some settings, are considerably older. These circumstances can increase their risk for HIV and other STIs, limiting their own well-being and also elevating the risk of maternal and child mortality. Young first-time mothers should be the subject of specially targeted programmatic efforts. ${ }^{46}$

Work outward from girls to best understand, and measure, the positive engagement of boys and young men in support of the health and well-being of vulnerable girls

The range of programming to reach men and boys on their own-as husbands, boyfriends, brothers, and fathers-has been increasing. Evidence indicates that initiatives that strongly promote equitable gender roles and relations can favorably influence attitudes and behaviors reported by boys and men. ${ }^{47}$ Programs have seldom started with girls and young women-asking them about the males in their lives (who may represent both protection and risk to their health and well-being), and finding out what they experience and what they feel needs to be changed. Such inquiry is needed to design interventions that work with the specific boys and men who have an impact on the lives of girls and young women. Measurement of the effectiveness of interventions to improve gender relations and positive male engagement should be undertaken with the male participants-but more importantly, with the females living with them. ${ }^{48}$

Mobilize girls and young women to strengthen the health sector and expand their livelihood horizons

Historically and culturally, girls and young women take on the vast share of caring for the sick in their homes and communities (caring for sick children, parents, grandparents, and those living with HIV and other chronic diseases). Disproportionate responsibility for such care can impede girls' education and 


\section{TABLE 3 ILLUSTRATIVE "WELLNESS CHECK" COMPONENTS}

\section{HEALTH}

Physical exam

Immunization review and catch-up

Nutrition/growth check-up

Sexual and reproductive health information and services

HPV vaccine (when available)

HIV and AIDS prevention information

Violence screening and support

Mental health screening and support

Injury screening and prevention

\section{SOCIAL}

Counseling

Life-skills building

Educational assessment and support

Peer and social-support screening and improvement

Drugs/alcohol/smoking screening and support for addiction prevention

Family wellness and social support

Citizenship and social-participation skill building and motivation their ability to obtain work outside the home and to pursue and maximize their full potential. More must be learned about the dimensions, implications, and cost of the true family- and communitybased health-care burden on girls and young women and how it can be made more equitable.

Programming with indigenous Mayan girls in Guatemala has illustrated that young women are engaged and working in the informal health sector, as traditional healers and birth attendants. ${ }^{49}$ Young women living in impoverished circumstances are constantly looking for safe, dignified livelihood options, including entering the health sector. Barriers exist, however, particularly for those from the poorest communities that need health services the most. This can potentially be transformed, but only if the health sector can find ways to train, support, and provide safe, dignified, and legitimate jobs for young women, for which they are compensated for their knowledge and skills. Often, the most vulnerable girls who end up in nonformal family- and community-caretaker roles are in those positions because the formal health sector does not extend to where they live. An effective strategy for the health sector would be to convert talented, motivated-and often multi- cultural and multilingual-young women into formal community-health outreach workers or health agents. Young women already engaged as traditional healers and birth attendants can be formally integrated into the health sector to build on and support what they are already doing. These women can help fill human resource gaps in rural or otherwise underserved communities.

Young women also can be trained and deployed to help respond to community and girls' health needs, including helping support the formal health sector at the primary-care level, where it reaches the most vulnerable. Efforts to bring young people into the health sector as peer educators and counselors have been undertaken in a range of countries. ${ }^{50}$ Furthermore, young women can be trained to:

- Undertake community-based distribution and social marketing of health technologies useful to the community at large (including water filters, clean cook stoves, and mosquito nets) as well as sexual and reproductive health commodities (such as female and male condoms);

- Guide and support mobile health-service delivery in their communities;
- Use other local non-health-sector venues (such as schools, pharmacies, markets, community-based organizations, churches, and girls' safe spaces programs) to deliver age, gender, and culturally appropriate health information and services.

Additional examples of vital skills for girls' community health promotion are listed in Table 4.

It is essential that young women are fairly compensated and effectively supported as they take on creative new roles in supporting and improving the reach and quality of the health sector at different levels.

Some nascent experiences using professional internships to provide girls with an opportunity to rotate through health and social-support programs are taking place at the community level in the public sector and local communities. In Guatemala, young indigenous female interns are being trained through the public sector to undertake violence-prevention activities and provide culturally appropriate, bilingual information and support to rape victims, who are often very young. ${ }^{51}$

There should be concerted efforts to make much more use of young women as health agents. By comparing 


\section{TABLE 4 ESSENTIAL SKILLS FOR GIRLS' COMMUNITY HEALTH PROMOTION}

BY AGE 10

Knows how to properly wash hands

Knows the name of the community health outreach worker and local nurse and doctor

Knows how to get to the nearest health center and hospital

Knows how to call emergency transportation

Can recognize the signs of diarrheal disease in an infant and adult

Can recognize danger signs during labor and delivery
BY AGE 14

Knows how to manage menstruation and feminine hygiene

Knows how the male and female reproductive systems work

Knows how to prevent unwanted pregnancy

Knows how HIV is transmitted

Knows how to use a condom

Knows where to get an HIV test

Can recognize and respond to situations of gender violence (has an emergency plan)

Has received comprehensive sexuality education girls' health vulnerabilities in a particular location with the availability of girls who have basic education-and thus the potential to become health agents of change-policymakers and program managers can find the best locations to make early investments. We can learn from girls and be guided by their insights about the best ways to alleviate their burden and maximize their potential.

\section{Educate girls and young women} to understand their rights and responsibilities as both health-care consumers and providers

All girls, especially the most vulnerable, must be made aware that they are entitled to comprehensive, accurate, and timely health information, education, counseling, and services. In addition to being aware of this for themselves, many girls and young women can be trained to provide these services at the community level (in both public and private health sectors), which can translate into safe, productive, and socially responsible livelihoods. In many instances, young women are uniquely positioned to serve as critical bicultural, bilingual bridges between families and communities and the health sector, building on roles they already play. Mobilizing and supporting young women as health agents is a win-win for girls and the health sector.

\section{RESOURCES: LEARNING LAB PROGRAMS, PUBLI- CATIONS, AND TOOLS}

\section{Abriendo Oportunidades: Working with girls in rural Guatemala to discover their health potential and reduce violence}

The Population Council's Abriendo Oportunidades $(\mathrm{AO})$ program is designed to reach and empower indigenous girls aged 8-18 in rural Guatemala. The program uses a "safe spaces" model to create opportunities for girls to come together regularly to increase their social support, learn life skills, help them stay in school, transition to safe livelihoods, and gain access to female role models and mentors. The program is experimenting with safe spaces as platforms for training girl leaders to deliver health education and some community health services. This is a strategy that needs to be tested and evaluated.

$\mathrm{AO}$ also plans to collaborate with a local micro-consignment NGO to train girl leaders to undertake education campaigns and sell community health commodities-e.g., water filters, mosquito nets, and reading glassesin their rural communities, keeping a small profit for themselves. For further information, please contact Population Council consultant Angel del Valle, adelvalle@popcouncil.org, or visit the project website at http:// www.popcouncil.org/projects/244_ CreateOpportunitiesMayan.asp.

\section{There should be} concerted efforts to make much more use of young women as health agents.

Rwanda 12+: Focusing systematic attention on the potential and needs of the 12-year-old girl

In Rwanda, the Ministry of Health, Ministry of Youth, and Ministry of Education are collaborating with the Population Council, DFID's Girl Hub, and the Nike Foundation in experimenting with a concept known as the "12+ check-in," during which girls are offered a range of health and social wellness services- 
a physical exam, immunization review and catch-up, violence screening and support, an education assessment and citizenship skill-building-timed to reach them at the critical moment around puberty. The intention of the initiative is to help girls stay or get on track by providing them with a comprehensive check-up that assesses their needs and connects them and their families to existing social services. The check-in will provide an opportunity to learn about and make course corrections concerning the often-hidden conditions of adolescent girls beyond the aggregated numbers. Health and demographic data can be collected and tracked to allow for longitudinal assessment of female health and wellness, pooling a subset of girls at critical ages. For further information, please contact Janna McDougall, at Janna.McDougall@nike.com.

\section{Berhane Hewan: Creating a place} to support unmarried and married girls and the youngest first-time mothers

In Amhara, Ethiopia, with early marriage comes early sexual initiation. Twenty-six percent of married girls had sex by age 12 , and 70 percent by age 15 . Fewer than one third (31 percent) of married girls had started menstruating when they had sex for the first time. Eightytwo percent of married girls did not want to have sex when they had sex for the first time, and 81 percent described their first sex as forced. The figures are even higher among girls married at earlier ages. Additional qualitative data highlight violence and a lack of consent.

In response, Berhane Hewan, implemented by the Population Council and the Ethiopia Ministry of Youth and Sports, reaches married and unmarried girls aged 10-19, and establishes appropriate and effective mechanisms to protect and support girls at risk of forced early marriage and married adolescent girls. Married girls-ranging in age from 11 to 20-gather at least once a week, on Sunday afternoons, for several hour sessions. They learn about their health and the prospective health of their children (many are already pregnant). They also learn about and gain access to family planning methods and evolve safety plans around their pregnancies. The support of these clubs resulted in a contraceptive use rate of 74 percent among married girls in the program, compared with 45 percent among married girls in a control village; increased very specific knowledge of the HIV risks within marriage; and an increased proportion of women and their partners who are getting tested for HIV. ${ }^{52}$ For further information, please contact the Population Council country director in Ethiopia, Annabel Erulkar, at aerulkar@ popcouncil.org, or visit the project website at http://www.popcouncil.org/ projects/

100_BerhaneHewanEthiopia.asp.

\section{Puntos de Encuentro: Addressing the nexus between violence and poor health}

Puntos de Encuentro is a local NGO based in Nicaragua with a mission to increase women's and young people's ability to take control over their own lives and participate in all levels of society. To achieve this mission, Puntos implements a multimedia/multimethod strategy that combines "edutainment" programs, social mobilization, and local capacity-building to encourage individual behavior change, interpersonal communication, social support, and collective action. An impact evaluation included quantitative and qualitative measures with a sample of more than 4,500 males and females aged 13-24. Results included significant reduction of stigmatizing and gender-inequitable attitudes, an increase in knowledge and use of HIV-related services, and a significant increase in interpersonal communication about HIV prevention and sexual behavior. Qualitative findings also indicated the program's important role in promoting community-based dialogue, strengthening youth leadership, and fostering alliances between organizations. The results further suggest that individual behaviors (e.g., consistent condom use in sexual relations) are not isolated from the environment in which people live, but rather are related to social contexts and processes. For more information, please contact Amy Bank, amy.bank@ puntos.org.ni or download a program description at http://www.endvawnow. org/pampa/v0.1/library/filemanager/ v1/files/Sexto\%20Sentido.pdf.

\section{Tools for work on girls and health}

It's All One Curriculum: Guidelines for a Unified Approach to Sexuality, Gender, HIV, and Human Rights Education

It's All One Curriculum is designed to help teachers, trainers, and youth leaders develop sexuality and HIV education curricula with an emphasis on gender and rights. It is intended to enable educators to teach young people about topics such as gender norms, communication, and decisionmaking, sexual consent and coercion; fairness and human rights (including sexual rights); power and relationships; preventing HIV, STIs, and unintended pregnancy; puberty; and social change. The guidelines are innovative in their integration of these topics, the focus on dynamic experiential teaching methodologies and the objective of teaching to foster critical thinking skills in adolescents. The two volumes bring together core content and participatory activities to teach it, as well as an additional resources section. This new material and approach can be adapted and evaluated with different subgroups of girls and young women in distinct contexts. It can be downloaded free of charge and is available in English, Spanish, and French at http://www.itsallone.org.

Investing When It Counts: Generating the Evidence Base for Policies and Programs for Very Young Adolescents

This publication provides guidance for policymakers and program managers about technical and ethical considerations in conducting research with and designing programs for very young adolescents, particularly girls, aged 10-14. It can be downloaded free of charge and is available in English and Spanish at http://www.popcouncil.org/ pdfs/InvestingWhenltCounts.pdf. 
WHO Adolescent Job Aid: A handy desk reference tool for primary-level health workers

The WHO Adolescent Job Aid is a desk reference tool for health workers (trained and registered doctors, nurses, and clinical officers) who provide services to children, adolescents, and adults. It aims to help these health workers respond to their adolescent patients more effectively and with greater sensitivity. It provides precise, stepby-step guidance on how to deal with adolescents when they present with a problem or a concern about their health or development. It can be downloaded free of charge at: http://www.who.int/ maternal_child_adolescent/documents/ 9789241599962/en/index.html.

\section{Girl-Centered Program Design: A Tool-} kit to Develop, Strengthen, and Expand Adolescent Girls Programs

The Girl-Centered Program Design toolkit is meant for those interested in working with adolescent girls aged 10-24. It can be used by anyone who is designing or running a program, someone writing a proposal to work with girls, or staff working directly with girls who need fresh ideas on how to strengthen program activities. It can be used by people who are starting to work with girls in a targeted way for the first time, or those who already have a girls program but are trying to strengthen or expand it. The toolkit has three main sections: The first focuses on structure, the second on content (including health), and the third on monitoring and evaluation. Within each chapter is an introduction to the topic, examples from existing programs for girls, and practical, user-friendly tools. It can be downloaded free of charge in English, Spanish, or French at http:// www.popcouncil.org/pdfs/2010PGY_ AdolGirlToolkitComplete.pdf.

\section{Empowering Young Women to Lead Change}

Empowering Young Women to Lead Change is a training tool for young wom- en to catalyze positive change in their lives and communities. It is designed by and for young women and covers the topics of sexual and reproductive health and rights; self-esteem and body image; violence against women; human rights; economic justice; and peace. The workshop guides included in each module are designed to enable young women to successfully lead fun and engaging workshops without need for "expert facilitators." The curriculum is flexible and allows for adjustments, such as special speakers or resource people, to suit the needs of the participants. The modules may be used alone or in any combination that best meets participants' interests, requirements, available time, and resources. It can be downloaded free of charge in English, Spanish, and French at http://www.worldywca.org/ Resources/YWCA-Publications/Empowering-Young-Women-to-Lead-Change.

\section{CONCLUSION}

If the current burden and risk experienced by young females can be turned into a "dual opportunity" by re-forming and creating a health system that is more equitable and sensitive to the needs of vulnerable adolescent girls and young women in their double-role as both health-care consumers and providers, then females, communities, and nations will develop and thrive. Investing in vulnerable girls and young women as both consumers and providers of health care will serve girls and their communities by stimulating both the demand for, and supply of, higher quality, gender- and age-appropriate health information and services at all levels, especially the primary level, where the most vulnerable are often found. Training, mobilizing, and compensating girls and young women as community health agents will create a vital new human resource to help bridge communities to the health sector and improve health outcomes for girls and communities as a whole.

\section{NOTES AND REFERENCES}

1 World Health Organization. 2009. Women and Health: Today's Evidence, Tomorrow's Agenda. Geneva.

2 Temin, M. and R. Levine. 2009. Start with a Girl: A New Agenda for Global Health. Washington, DC: Center for Global Development.

3 United Nations Children's Fund. 2011. The State of the World's Children. 2011. New York: UNICEF.

4 Ibid.

5 Levine, R. 2007. Case Studies in Global Health: Millions Saved. Boston: Jones and Bartlett.

6 World Health Organization. 2003. Strategic Directions for Improving the Health and Development of Children and Adolescents. Geneva.

7 Lloyd, C.B. (ed). 2005. Growing Up Global: The Changing Transitions to Adulthood in Developing Countries. Washington, DC: The National Academies Press.

8 Lloyd, C.B. 2009. New Lessons: The Power of Educating Adolescent Girls. A Girls Count Report on Adolescent Girls. New York: Population Council.

9 United Nations Children's Fund. 2008. The State of the World's Children 2009: Maternal and Newborn Health. New York: UNICEF.

10 Lloyd (2005) op. cit.

11 Mensch, Barbara, Judith Bruce, and Margaret E. Greene. 1998. The Uncharted Passage: Girls' Adolescence in the Developing World. New York: Population Council.

12 Nahar Q. and R. Ahmed. 2006. Addressing Special Needs of Girls' Challenges in School. Presented at SACOSAN II. Islamabad, Pakistan.

13 World Health Organization. 2011. An Up date on WHO's Work on Female Genital Mutilation. Geneva.

14 UNICEF (2011) op. cit.

15 Ibid.

16 Agosti, J.M. and S.J Goldie. 2007. "Introducing HPV vaccine in developing countries-Key challenges and issues," New England Journal of Medicine 356: 1908-1910. 
17 Garcia-Moreno, C. et al. 2005. WHO Multi-country Study on Women's Health and Domestic Violence. Geneva: World Health Organization.

18 Khan M.E. et al. 2008. A Situation Analysis of Care and Support for Rape Victims at First Point of Contact in India and Bangladesh. New York: Population Council.

19 Lloyd (2005) op cit.

20 Ibid.

21 Piwoz, E. and E. Greble. 2000. HIV/AIDS and Nutrition: A Review of the Literature. Washington, DC.

22 World Health Organization. 2009. Women and Health: Today's Evidence, Tomorrow's Agenda. Geneva.

23 UNAIDS. 2008. Report on the Global AIDS Epidemic. Geneva.

24 Global AIDS Alliance. 2010. Violence against Women and Children and HIV/ AIDS. Washington, DC.

25 World Bank. 2006. World Development Report 2007: Development and the Next Generation. Washington, DC.

26 United Nations Platform for Action Committee. "Women \& the Economy: Globalization and Migration." < http:// www.unpac.ca/economy/g_migration. html>.

27 WHO (2009) op. cit.

28 Ibid.

29 World Health Organization. 2007. Sifting the Evidence: Gender and Tobacco Control. Geneva.
30 Austrian, K. and D. Ghati. 2010. GirlCentered Program Design. Kenya: Population Council.

31 World Health Organization. 2002. Adolescent Friendly Health Services: An Agenda for Change. Geneva.

32 World Health Organization. 2010. Adolescent Job Aid: A Handy Desk Reference Tool for Primary Level Health Workers. Geneva.

33 World Health Organization, Commonwealth Medical Association Trust, and UNICEF. 2006. Orientation Programme on Adolescent Health for Health-care Providers. Geneva.

34 WHO (2009) op. cit.

35 Brabin, L., B.J. Brabin. 2005. “HIV, malaria and beyond: Reducing the disease burden of female adolescents," Malaria Journal. 2005, 4:2.

36 WHO (2009) op. cit.

37 Abriendo Oportunidades program. 2011. Guatemala: Population Council.

38 Catino, J., A. Colom and M.J. Ruiz. 2011. Equipping Mayan Girls to Improve Their Lives. New York: Population Council.

39 UNICEF. 2009. A Study on Violence against Girls: Report on the International Girl Child Conference. The Hague, Netherlands.

40 Abriendo Oportunidades program. 2010. Guatemala: Population Council.

41 It's All One Curriculum. 2009. New York: Population Council.
42 Puntos de Encuentro: Sexto Sentido. Nicaragua. <http://www.sextosentidotv. com>.

43 Because I am a Girl: Digital and Urban Frontiers: Girls in a Changing Landscape. 2010. United Kingdom: Plan International.

44 "Mobile Alliance for Maternal Action." <http://www.mobilemamaalliance.org>.

45 Bruce, J. 2008. The 12-Year Old CheckIn. New York: Population Council.

46 Haberland, N. "Supporting married girls: Calling attention to a neglected group." Transitions to Adulthood. New York: Population Council. December 2007.

47 Barker G., C. Ricardo and M. Nascimiento. 2007. Engaging Men and Boys in Changing Gender-Based Inequity in Health: Evidence from Program Interventions. Geneva: WHO and Promundo.

48 Bruce, J. et al. 2011. First Generation of Gender and HIV Programs: Seeking Clarity and Synergy. New York: Population Council.

49 Abriendo Oportunidades program. 2011. Guatemala: Population Council.

50 Provide: Strengthening Youth Friendly Services. 2008. London: IPPF.

51 Abriendo Oportunidades program. 2011. Guatemala: Population Council.

52 Erulkar, Annabel. 2008. "Evaluation of Berhane Hewan Program in Addis Ababa, Ethiopia." Population Council. 


\section{(2) Population Council}

The Population Council confronts critical health and development issues-from stopping the spread of HIV to improving reproductive health and ensuring that young people lead full and productive lives. Through biomedical, social science, and public health research in 50 countries, the Council works with our partners to deliver solutions that lead to more effective policies, programs, and technologies that improve lives around the world. Established in 1952 and headquartered in New York, the Council is a nongovernmental, nonprofit organization governed by an international board of trustees.

www.popcouncil.org 